\title{
A Rare Cause of Air Inside an Aortic Aneurysm Thrombus
}

\author{
Asim Kalkan (D), Selman Yeniocak \\ Clinic of Emergency Medicine, Haseki Training and Research Hospital, Istanbul, Turkey
}

Cite this article as: Kalkan A, Yeniocak S. A Rare Cause of Air Inside an Aortic Aneurysm Thrombus. Eurasian J Emerg Med. 2018; 17: 87-8.

A 59-year-old male patient presented to our emergency department with abdominal pain and fever. He had undergone endovascular aneurysm repair (EVAR) due to the presence of a thoracoabdominal aortic aneurysm approximately 2 years ago. His vital signs were as follows: arterial blood pressure: $90 / 50 \mathrm{mmHg}$, respiration rate: $22 /$ min, heart rate: $120 / \mathrm{min}$, body temperature: $39^{\circ} \mathrm{C}$, and fingertip oxygen saturation: $95 \%$. His abdo men was tender during the physical examination, but there was no rebound or defense. Other system examinations were normal. His laboratory test results were as follows: leukocyte count: 14,100 $\mu \mathrm{L}$ (normal: 4230-10200), hemoglobin level:
$11.3 \mathrm{~g} / \mathrm{dL}$ (normal: 12.2-16.2), platelet count: 381,000 $\mu \mathrm{L}$ (normal: 142000-424000), and CRP level: $113.5 \mathrm{mg} / \mathrm{L}$ (normal: 0-5 mg/L). Liver and kidney function test results were normal. Thoracic and abdominal contrast computed tomography (CT) were performed (Figure 1). Diffuse air was seen around the thrombus inside the aneurysm lumen from the lower thorax to the renal artery. We suspected that the air inside the aneurysm lumen was associated with the presence of an aortoenteric fistula. Intravenous and oral contrast CT were performed, but no fistula was observed (Figure 2).

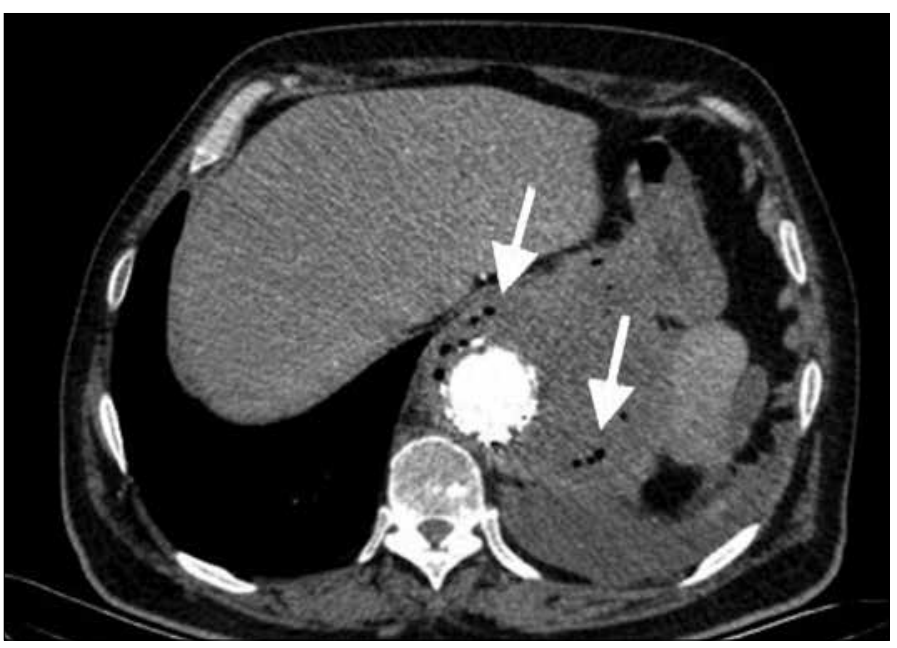

Figure 1. Air inside the thrombus (abdominal tomography of the patient with intravenous contrast)

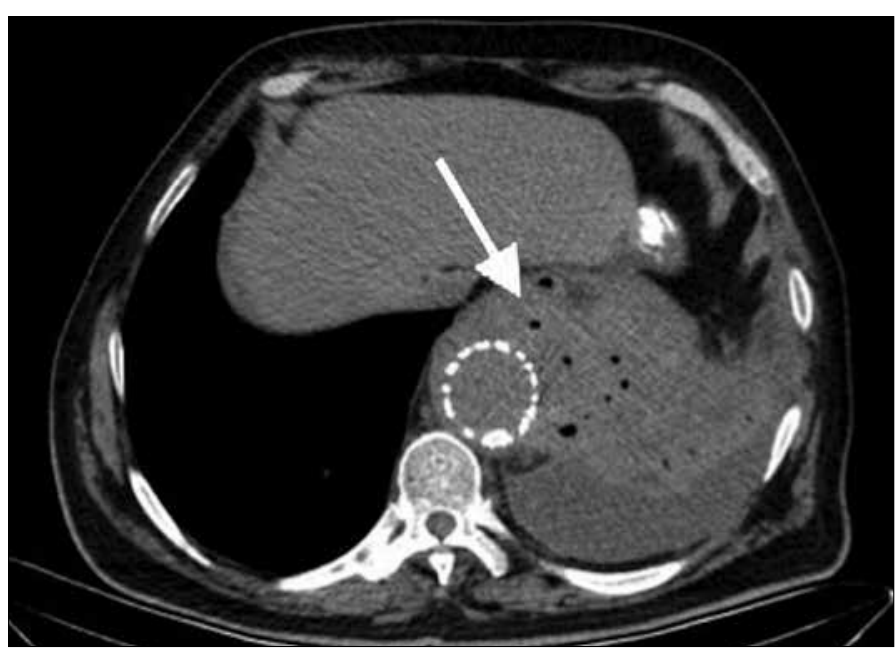

Figure 2. Air inside the thrombus (abdominal tomography of the patient with intravenous and oral contrast)

ORCID ID of the author: A.K. 0000-0002-5800-0201. 


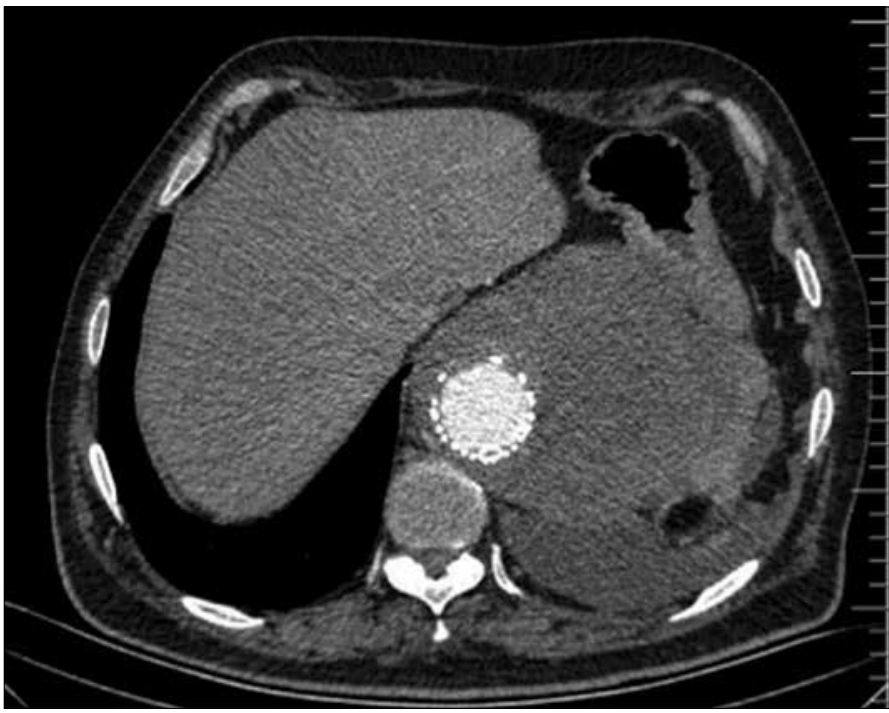

Figure 3. Complete resorption of air following treatment

\section{Diagnosis: Sepsis}

Some air may be present around stents following EVAR. This is generally associated with air leakage occurring during the procedure. However, this air is generally resorbed within 3 months. If there is no air inside the thrombus after the procedure and air is subsequently present, stent infection is usually the cause, and the stent must be removed. This generally occurs a few weeks after stent implantation (1). When we accessed our patient's abdominal tomography image taken 3 months after EVAR, there was no air inside the thrombus. It is rare for air to be seen inside a thrombus around the aortic lumen, and this should suggest the presence of an aortoenteric fistula. The best means for detecting such a fistula is oral and intravenous contrast CT (2). Enteric fistulas can cause air embolism, and air passing from the enteric area to the aorta can also penetrate the thrombus. Our patient had no fistula. We suspected sepsis as the principal cause of air inside the thrombus. Bacteria settling inside the thrombus in association with bacteremia occurring during sepsis can produce air. Images such as those obtained in our case may therefore be obtained. Following broad-spectrum antibiotic therapy, the air inside the thrombus disappeared on last CT Figure 3).

If there is air in the aortic thrombus, we have to keep the following four conditions in mind:

1- Endovascular aneurysm repair (EVAR)

2- Stent infection

3- Aortoenteric fistula

4- Sepsis

Informed Consent: Not required in this study.

Peer-review: Externally peer-reviewed.

Author Contributions: Concept - A.K.; Design - S.Y., A.K.; Supervision - A.K.; Resources - S.Y.; Materials - S.Y.; Data Collection and/or Processing - A.K.; Analysis and/or Interpretation - S.Y., A.K.; Literature Search - S.Y., A.K.; Writing Manuscript - A.K.; Critical Review - S.Y., A.K.

Conflict of Interest: The authors have no conflict of interest to declare.

Financial Disclosure: The authors declared that this study has received no financial support.

\section{References}

1. Holden A, Savlovskis J, Winterbottom A, van den Ham LH, Hill A, Krievins D, et al. Imaging After Nellix Endovascular Aneurysm Sealing: A Consensus Document. J Endovasc Ther. 2016; 23: 7-20. [CrossRef]

2. Kay MD, Davies B, Patel K, Gourevitch D. Aorto-oesophageal fistula following TEVAR: an unusual cause of mediastinal air. BMJ Case Rep. 2013: pii: bcr2013009268. 